
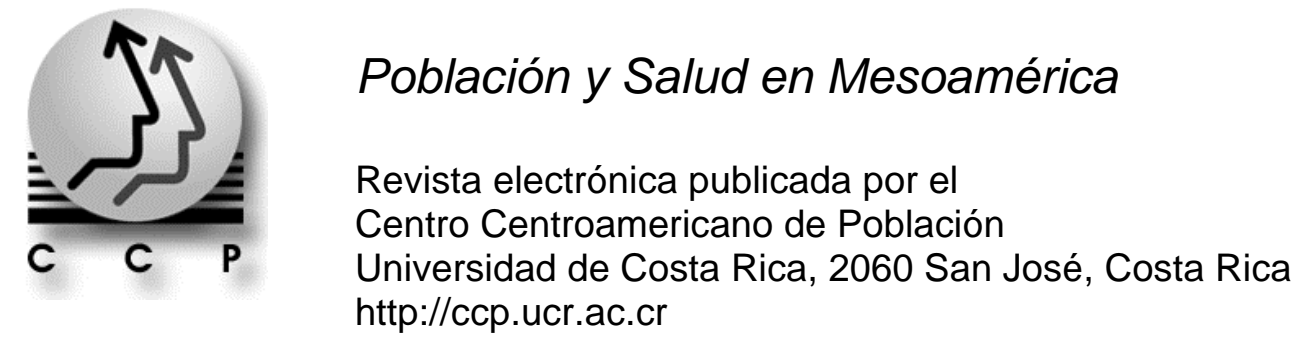

Población y Salud en Mesoamérica

Revista electrónica

Volumen 3, número 2, artículo 4

Enero - junio, 2006

Publicado 1 de enero, 2006

http://ccp.ucr.ac.cr/revista/

\title{
Migración y políticas públicas: elementos a considerar para la administración de las migraciones entre Nicaragua y Costa Rica
}

\section{Dalia Borge}

(C) 2006 Centro Centroamericano de Población 


\title{
Migración y políticas públicas: elementos a considerar para la administración de las migraciones entre Nicaragua y Costa Rica
}

\author{
Dalia Borge ${ }^{1}$
}

"Los países de bajo o mediano ingreso ven la emergencia del mercado de trabajo como una oportunidad para expandir el empleo, sacar provecho al intercambio internacional y reducir el descontento social, especialmente el de la gente joven que ve frustradas sus aspiraciones de progreso a través de la inversión en educación. Sin embargo, el empleo de trabajadores extranjeros va acompañado de la explotación y de la violación de sus derechos” (Abella, 1997).

\section{RESUMEN}

El artículo se refiere a que no existen políticas públicas migratorias en Costa Rica para administrar este fenómeno. Critica la posición del Estado - que justifica su falta de actuación en políticas relevantes para sus nacionales - con respecto al impacto de la migración de nicaragüenses en los diferentes servicios que este presta, sin tener ningún fundamento. El artículo explica la importancia de llevar a cabo una política migratoria en doble dimensión (desde el Estado receptor y desde el emisor) a través de una política pública y de una política exterior de empleo. Expone los factores que deberían contener ambas políticas.

\section{ABSTRACT}

The article refers that do not exist public politics of migration in Costa Rica to administer this phenomenon. It criticizes the position of the State - that justifies his lack of performance in political relevant for his natives - with regard to the impact of the Nicaraguans' migration in the different services that this one gives, without having any foundation. The article explains the importance of taking to end a migratory politics in double dimension (from the State recipient and from the issuer) across a public politics and an exterior(foreign) politics of employment. It exposes the factors that should contain political both.

\footnotetext{
${ }^{1}$ Doctora en Gobierno y Políticas Públicas, Universidad de Costa Rica. Investigadora Centro Centroamericano de Población dborge@ccp.ucr.ac.cr
} 


\section{INTRODUCCIÓN}

La migración internacional es un fenómeno que se ha constituido en un tema que requiere un tratamiento especial en las políticas de los países. La globalización, la apertura comercial y la integración regional, traen consigo no solo la movilización de bienes y servicios sino también de conocimiento y de mano de obra. La migración es por lo tanto, un tema que debe ser tomado son seriedad por los gobiernos del orbe, al lado de la conservación del medio ambiente y la equidad social (Mármora, 2002:13).

La movilización humana no es un proceso mecánico, no se puede detener por medio de instrumentos políticos. Si bien podemos contabilizar el número aproximado de personas que salen de su país de origen en busca de otros territorios, no podemos aplacar sus deseos de buscar oportunidades para tener una vida en condiciones más favorables a las que experimentan en su propio país. Lo que si es posible hacer es administrar los flujos migratorios por medio de políticas que tomen en consideración a la población migrante, sus derechos y obligaciones, así como el contexto político, económico y social del país que los recibe.

El punto de partida desde cual situarse para canalizar los flujos migratorios no es la seguridad. Se trata más bien de un desafío humano, y como tal merece un tratamiento orientado a aprovechar los aspectos que contribuyen con el desarrollo de las sociedades involucradas en el proceso migratorio desde un tratamiento administrativo y político adecuado.

Pero al lado de las políticas que puedan surgir por las preocupaciones que la presión migratoria pueda estar ejerciendo sobre la gestión de un gobierno, debe de ordenarse la información referente a este fenómeno entre los académicos y estudiosos, con el fin de transmitir el conocimiento de la realidad a los que toman las decisiones políticas. Es decir, que es preciso establecer un diálogo efectivo entre los diferentes actores sociales, políticos y académicos para generar políticas públicas que favorezcan el desarrollo de los países involucrados en el fenómeno migratorio.

El presente artículo pretende realizar un primer acercamiento a los elementos que requiere una política pública para administrar el fenómeno migratorio que se presenta entre Nicaragua y Costa Rica.

La hipótesis que guía esta investigación se refiere a que no existe una política pública migratoria en Costa Rica que se oriente bajo el esquema de una gestión pública ordenada. Lo anterior se debe, entre otras cosas, al deterioro de las políticas en otros sectores prioritarios como la salud, la educación y la vivienda, entre otros, para los nacionales. Las consecuencias que la inexistencia de políticas públicas migratorias podrán ser entre otras la xenofobia, violación de derechos humanos, deterioro de los servicios de salud, educación, vivienda, y deterioro de las relaciones exteriores con consecuencias en las relaciones políticas y comerciales entre Costa Rica y Nicaragua. 


\section{¿EXISTE UNA POLÍTICA PÚBLICA MIGRATORIA EN COSTA RICA?}

Las política públicas son programas de acción que lleva a cabo una autoridad pública (Meny Thoenig, 1992:9) y que reflejan las prioridades de una administración. Si bien existen más de diez Convenios y Recomendaciones de la Organización Internacional del Trabajo $(\mathrm{OIT})^{2}$ en relación con la protección de los derechos de los trabajadores migrantes, Costa Rica no ratificado ninguno. Además también se han llevado acuerdos binacionales entre Costa Rica y Nicaragua en materia migratoria laboral. El Convenio de mano de obra migrante de 1993, fue el resultado de las diferentes reuniones que los representantes de ambos países realizaron y cuyo objetivo era complementar los mercados laborales de ambos países, a través de vías legales para el ingreso de nicaragüenses a Costa Rica y así eliminar las consecuencias negativas de la migración irregular. Esta dirigido especialmente a los trabajadores de la agricultura y pretende darle un trato equitativo a los trabajadores nicaragüenses con respecto a los costarricenses. Este Convenio sirvió de base para la creación mediante decreto ejecutivo de la Tarjeta de Trabajo Estacional ${ }^{3}$, que dejó de aplicarse en 1998. La legislación costarricense contempla en general la salvaguarda de los deberes y derechos de los trabajadores costarricenses que se debe de aplicar a los extranjeros que trabajen en el país de manera legal. Sin embargo, ninguna de estas acciones está contemplada dentro de un programa de acción dirigido especialmente a la migración como un tema de relevancia en la administración de las cuestiones públicas.

Lo anterior, apunta a que no existen políticas públicas dirigidas a la migración internacional en general como un fenómeno social de importancia que merece una atención especial. Por otra parte, cuando se han llevado a cabo algunas acciones como es el caso de la Tarjeta de Trabajo Estacional, el Estado no ha sabido orientar las políticas para cumplir con lo establecido. Así lo muestra un estudio realizado en 1995 por la OIT, que determinó que el Estado Costarricense carecía de medios eficaces para vigilar que se cumpla la legalidad; identificó al empresariado costarricense como uno de los sectores que fomentaba la ilegalidad de los migrantes trabajadores; y una marcada ausencia de consulta a los diferentes sectores sociales en relación con la temática.

Las políticas públicas pueden tratar los temas sociales de manera aparentemente aislada, sin embargo, debido a que se dirigen a los sujetos sociales, se implican unas con las otras. Por esa razón las políticas públicas migratorias laborales, toman en consideración las políticas laborales, las de educación, las relacionadas con la vivienda, las de salud, y las de seguridad ciudadana, entre otras. Si un Estado lleva a cabo políticas públicas que procuran el desarrollo de sus ciudadanos, estas beneficiarán también a los extranjeros. Caso contrario, cuando un Estado no cuenta con políticas públicas dirigidas a mejorar la calidad de vida de sus nacionales, los extranjeros también se verán perjudicados directa o indirectamente. No se puede responsabilizar a un colectivo de migrantes trabajadores por la no acción o descuido del Estado receptor en materia de políticas públicas. Esto solo es un intento de justificar su inoperancia dirigiendo su responsabilidad a un contingente al cual tampoco es capaz de administrar. Así las políticas públicas en temas relevantes como

\footnotetext{
${ }^{2}$ Convenio N.97 de 1949, Recomendación N.86, Convenio N.143 de 1975 y la Recomendación N.151.

${ }^{3}$ Decreto Ejecutivo N.24432-TSSG-G, de la Administración Figuerez Olsen 1994-1998
} 
la salud, la vivienda y la educación para los costarricenses no son las más adecuadas. El impacto del deterioro en el sistema de seguridad social, por ejemplo lo sienten tanto nacionales como extranjeros. Y está demostrado a través de estudios, que el impacto en ese deterioro por parte de los migrantes no es significativo. De acuerdo con un estudio realizado por Jorge Barquero (2005), el 42\% de hombres nicaragüenses y el 22\% de hombres costarricenses no tienen un seguro social en Costa Rica. De igual manera, el $38 \%$ de las mujeres nicaragüenses y el 15\% de las mujeres costarricenses, no cuentan con seguro social. El seguro por cuenta del Estado cubre al 9\% de los ticos y al 7\% de los nicaragüenses. Finalmente, cuentan con seguro directo y familiar el $75 \%$ de los costarricenses y el 53\% de los nicaragüenses. Este mismo estudio demuestra que los nicaragüenses no son la causa de la pobreza, pues su peso relativo no incide en las tendencias nacionales. Si bien los EBAIS son utilizados un $30 \%$ más por los nicaragüenses que por los costarricenses, no existe evidencia que demuestre que este colectivo sea el responsable del deterioro de los servicios de salud costarricenses. Por otra parte el 76\% de los extranjeros que viven en Costa Rica, tiene algún tipo de seguro. No se cuenta con estudios que determinen si los trabajadores nicaragüenses no asegurados por sus patrones costarricenses, estén utilizando los servicios de salud a tal nivel que impacten el sector significativamente. De acuerdo con Barquero (2005), los nicaragüenses utilizan los servicios de salud en menor proporción que el porcentaje que representan en el país ${ }^{4}$. En todo caso sería necesario preguntarse si no son más bien los patronos que al no pagar lo correspondiente al seguro de sus trabajadores - nacionales o extranjeros- los que en realidad estén deteriorando esos servicios.

\section{UNA POLÍTICA PÚBLICA MIGRATORIA COMPLEJA}

La migración es en sí un fenómeno que considera diferentes elementos de la vida en sociedad. En el momento en que los flujos migratorios se inician para recorrer la geografía entre por lo menos dos países, cuando se atraviesan las fronteras dibujadas por las administraciones públicas, se inicia un complejo entramado de circunstancias que requieren de una atención igualmente compleja. Solo hay que empezar por tomar en consideración que el concepto mismo de la migración aún no ha podido ser clarificado entre los teóricos y estudiosos del fenómeno. No se tiene todavía una tipología clara de la migración, desde las diferentes corrientes teóricas que este fenómeno trata. "El término migración hace referencia a uno de los fenómenos sociales más importantes de nuestra era, formando parte del común acervo cultural y lingüístico. Sin embargo, no existe una definición operativa que nos permita diferenciar claramente qué movimientos de población pertenecen a esta categoría y cuáles, por el contrario se escapan a ella” (Blanco, 2000:14).

El concepto de migración es difuso. No obstante, es necesario tener como punto de partida de qué se trata la migración a la que se quiere hacer alusión. El simple hecho de moverse de un sitio a otro no tiene la connotación suficiente como para causar un impacto tanto en el lugar del cual se parte, como al cual se llega. Es decir, que no todo movimiento puede considerarse migración desde una dimensión que requiera de un

${ }^{4} 6 \%$ de hospitalizaciones y 4\% de consulta externa y emergencias en el 2001. 
tratamiento político-administrativo. Por otra parte, de una clarificación del concepto de migración depende el tratamiento adecuado a los sujetos que participan en este proceso. Si el concepto de la migración es difuso, consecuentemente las categorías que de este se deriven lo serán también. El inconveniente de la falta de clarificación conceptual a este nivel consiste en que se "deja vía libre al lenguaje común para elaborar sus propias categorías y términos en función, muchas veces, de la circulación y difusión de estereotipos y prejuicios dominantes” (Blanco, 2000:15). Esta falta de clarificación conceptual tiene consecuencias en la toma de decisiones públicas con respecto al fenómeno migratorio. No es lo mismo hablar de un extranjero que de un migrante, como tampoco lo es hablar de un inversionista, un turista, un pensionado que quiere pasar los últimos días de su vida en un país distinto al que nació. El migrante es en consecuencia una categoría diferente de no nacional que tiene como parte de sus características necesidades básicas que cubrir, sobre todo la de un empleo. En su gran mayoría, no salen de su territorio por elegir entre alternativas que les favorezcan o les generen un valor agregado, lo hacen porque no tienen alternativa. Es una elección forzosa, guiada por la necesidad. Por lo tanto, la categorización de los individuos que se movilizan de un territorio tiene una carga que corresponde a su estatus quo, a su posición económica y social.

\section{EL CONCEPTO DE MIGRACIÓN Y SUS CONSECUENCIAS EN EL TRATAMIENTO DE POLÍTICAS PÚBLICAS}

¿Qué se entiende por migración? Se trata de un concepto poroso y difuso. Sin embargo, es necesario delimitar y clarificar un fenómeno que deja rastros sociales, económicos, culturales y políticos en las sociedades que involucra en su dinámica. Un camino para acercarse a este concepto es analizar los elementos que permiten caracterizar a la migración como tal.

En primer lugar la migración puede ser interna o internacional. El interés de este artículo se centra en la migración internacional, no obstante dentro de los elementos que Jackson (1986) considera importantes para definir la migración incluye el espacial indicando que el movimiento ha de producirse entre dos delimitaciones geográficas significativas. Este elemento hace referencia a la distancia, incluyendo regiones y provincias dentro de un mismo país o fuera de las fronteras nacionales. No obstante, el acento en la delimitación geográfica significativa es relativo. La infraestructura en carreteras y los medios de transporte hacen que la distancia sea mayor o menor, debido al nivel de dificultad para trasladarse de un lugar a otro. Puede ser que un grupo de migrantes viva geográficamente cerca del lugar al que ha decidido trasladarse, pero que a la hora de hacer efectivo su traslado, se encuentre con que no hay medios de trasporte adecuados, tenga que realizar parte del recorrido a pie o a caballo, que las carreteras no sean transitables. En comparación con otro grupo de migrantes que se encuentra quizás a mayor distancia con respecto al mismo destino, pero que cuenta con infraestructura vial y medios de transporte que harán que la distancia se recorra en un tiempo equivalente o menor con respecto al otro grupo en desplazamiento. 
Para que se pueda llamar a un movimiento de personas migración es necesario tomar en consideración de qué cantidad de personas se trata con respecto al país de procedencia como al de llegada. Esto significa que dependiendo de la magnitud de la población que se movilice de un territorio a otro, podemos decir que se trata de migración. La cantidad significativa de personas que salen de su territorio es un signo de que algo no está bien en el país del que proceden. Esto hace la diferencia, por ejemplo, con una familia que decide salir de su país para ubicarse en otro que tenga un mejor clima para vivir, mejores playas, un paisaje más agradable. Desde otro nivel de análisis se podría indagar en las causas que motivan un desplazamiento masivo y sistemático que pueden ser de diferente índole: económico, desastres naturales, político-militares entre otros.

El proceso migratorio afecta al menos dos sociedades desde diferentes perspectivas y en magnitudes que impactan su macroestructura. El movimiento migratorio se hace relevante para los países involucrados que experimentan cambios significativos en su estructura económica y social.

El desplazamiento además, tiene que ser duradero y no esporádico de acuerdo con Jackson (1986). Habría que delimitar a qué se refiere un movimiento duradero, cuantificándolo por ejemplo, en años. Este aspecto se puede relacionar con elementos coyunturales que provocan que los habitantes de un país se desplacen a otro. Por ejemplo, un terremoto puede provocar que un número significativo de personas se movilice, pero una vez que la emergencia se ha superado estas personas, pueden devolverse a su lugar de origen. Cuando por el contrario se trata de un elemento estructural, como lo es una crisis económica, la migración tiene un comportamiento diferente. En ese sentido, los países afectados por la migración pueden determinar si se trata de un acontecimiento que merezca un tratamiento de corto, mediano o largo plazo.

Desde una dimensión social, Jackson (1986) dice que el traslado debe suponer un cambio significativo de entorno social y físico. Esta delimitación es más ambigua que las anteriores en cuanto que el entorno social es igualmente difuso. Sobre todo cuando se trata de sociedades que tienen mucho en común por compartir una misma región, historia, costumbres.

Entonces para que un movimiento sea considerado migración debe de producirse entre dos espacios geográficos significativos; movilizar a una cantidad de población numéricamente importante; involucrar al menos dos sociedades; el movimiento debe de ser duradero; y suponer un cambio significativo de entorno social y físico para los colectivos implicados. Aunque este concepto ofrece de manera general las características que delimitan a la migración, cada fenómeno particular puede agregar aspectos que se reconozcan como relevantes en su caso concreto.

La migración de nicaragüenses hacia Costa Rica proviene de diferentes regiones, pero se hace énfasis en las fronterizas. De acuerdo con los datos del Censo de Población del año 2000, en Costa Rica había a la fecha 226.374 nicaragüenses, lo que significa aproximadamente el 6\% con respecto a la población total de costarricenses. Estos movimientos se han realizado por oleadas en diferentes momentos y por diferentes 
causas. De 1984 al 2000 los nicaragüenses pasaron de representar el 51.6\% al 76.4\% del total de extranjeros en Costa Rica. En cuanto a las implicaciones del entorno social y físico de estos colectivos, es necesario profundizar en aspectos que determinen en qué medida esta población es afectada por el entorno que la recibe. Por otra parte, es necesario tomar en consideración además las connotaciones histórico-culturales que vinculan a ambas sociedades. Solo por citar un dato el 10\% de los hogares costarricenses tienen algún tipo de parentesco con nicaragüenses (Vargas, 2003:3).

Las implicaciones que la migración tiene sobre los países involucrados en el proceso son de diferente índole y por lo tanto, la migración internacional tiene características especiales que la diferencian de otras tanto en el tiempo como en el espacio. Eso hace también que su tratamiento político administrativo sea diferente para cada caso. Sin embargo, los modelos en políticas públicas migratorias que otros países han desarrollado son un excelente ejemplo a considerar para conocer los aciertos y desaciertos que faciliten acerarse a una propuesta de política pública adecuada para el caso de Costa Rica y Nicaragua.

Para plantear una política pública migratoria es necesario tomar en consideración los elementos estructurales de los países implicados en el fenómeno como los son los históricos, económicos, políticos, sociales y culturales; elementos coyunturales como las crisis económicas, políticas, militares, los desastres naturales; el impacto de los cambios internacionales como la globalización, los esquemas de integración, los tratados comerciales; la normativa existente tanto nacional como internacional y los ejemplos que existen en cuanto a políticas públicas migratorias en otros contextos.

Plantear una política pública migratoria también tiene que tomar en consideración las demandas que las sociedades (emisora y receptora) tiene con respecto al tema. Los diferentes grupos de presión, las organizaciones no gubernamentales, asociaciones, la prensa, grupos de interés, investigadores, generan aportes para la discusión y el análisis desde diferentes puntos de vista.

La formulación de políticas públicas no es un proceso mecánico, todo lo contrario, elaborar una política pública, no es cuestión de sentarse a analizar los pro y los contra que una determinada temática requiere para ser tratada. Las políticas públicas toman en consideración a diferentes actores sociales y políticos que determinan de acuerdo con las relaciones de poder vigentes y el contexto en su sentido amplio, cual es el curso de acción a seguir para administrar los diferentes temas y desafíos para el Estado. Por eso autores como Lindblom (1991:13) se refieren a la elaboración de políticas públicas como un proceso muy complejo sin principio ni fin y cuyos límites permanecen muy inciertos. Es decir que las políticas públicas obedecen no solo al avance racional de los análisis de un determinado fenómeno, sino que "de alguna manera una red compleja de fuerzas produce conjuntamente un efecto llamado políticas públicas”.

El tema de las migraciones laborales de nicaragüenses, requiere ser atendido desde sus diferentes dimensiones. Para los analistas y teóricos de la migración ni siquiera está claro cuales son las implicaciones que para los países implicados tiene de manera positiva o 
negativa este fenómeno. Desde la política, este tipo de cuestiones tiende a resolverse mediante las “elecciones, mediante el voto legislativo o , mucho más a menudo, mediante la delegación de responsabilidades para la decisión en algunos funcionarios designados o nombrados que deben decidir la cuestión sobre si hay o no tiempo y fondos para el análisis” (Lindblom, 1991:36).

La reciente Ley de Migración y Extranjería, aprobada por la Asamblea Legislativa de Costa Rica (2005), es una muestra de que la política más que el análisis ha determinado las políticas a seguir “es decir que las políticas se elaboran a través de los distintos mecanismos por los que la gente ejerce control, influencia o poder sobre otros" (Lindblom, 1991:39). Esto es también el resultado de la evidente atomización que en materia de investigación existe en este país y de la ausencia de un mecanismo efectivo para comunicar los resultados desde la academia y de los diferentes institutos de investigación a la sociedad en general y principalmente a los que toman las decisiones políticas.

La información existente en relación con el estado de la migración de nicaragüenses en Costa Rica es muy variada, se ha abordado desde diferentes aristas y perspectivas metodológicas, pero está carente de alternativas que permitan visualizar de manera concreta las acciones a seguir para contribuir con una política coherente con las necesidades de los países involucrados con la migración. Lo anterior quiere decir que es necesario aunar esfuerzos hacia líneas de investigación que profundicen en los aspectos de mayor impacto del fenómeno como por ejemplo el mercado, la economía, la seguridad social, la integración étnica, entre otros. Estos análisis deberían de orientarse a diferentes audiencias con el lenguaje adecuado. No es lo mismo dirigirse a los académicos que los políticos, un grupo de estudiantes o los ciudadanos. De esa manera el análisis puede convertirse en un aliado estratégico para la toma de decisiones más acertadas en la política y que desde una visión de costo-beneficio le ahorraría en el mediano y largo plazo recursos al Estado y ayudaría a que las soluciones sean más viables si se toma en consideración que en tanto más se conozca de un fenómeno, existen mayores probabilidades de ser asertivo en las soluciones propuestas.

\section{DEFINIENDO UNA POLÍTICA PÚBLICA MIGRATORIA Y UNA POLÍTICA EXTERIOR DE EMPLEO}

De acuerdo con Charles Limblom (1991:13) la elaboración de las políticas públicas es un proceso muy complejo sin principio ni fin y cuyos límites permanecen muy inciertos. Además no es claro y dependiendo del tema de que se trate, podría tener diferentes niveles de complejidad. La migración, como se explicó anteriormente es un fenómeno multidimensional al que hay que darle un espacio importante en la agenda gubernamental, no solo del país que recibe migrantes sino del que los emite. Está más que probada la importancia que en el contexto mundial actual tienen las migraciones, y su influencia en la dinámica de la industrialización y la aceleración del libre comercio. En 
Europa, las políticas migratorias están basadas en tres ejes: el control de los flujos ${ }^{5}$, la integración de los inmigrantes establecidos y en una política de cooperación para reducir la presión migratoria (Criado, 2001). Estos ejes contienen la mayoría de los aspectos relevantes a considerar en un programa de acción de los Estados involucrados en la dinámica migratoria internacional (ver dibujo1), que podrían servir de ejemplo a seguir en otros contextos.

La migración laboral y su integración dentro de los países que los emplean tiene implicaciones particulares en la política doméstica tanto de los países emisores como receptores de migrantes, así como en las relaciones que se establecen entre ellos y hasta en el debate sobre las políticas de desarrollo económico” (Abella, 1997:1). Esta es una de las razones que hacen necesaria una intervención estatal de doble vía a través de políticas públicas que tomen en consideración las características de las comunidades implicadas en la migración. Además si se trata de países que tienen una dinámica de movimientos de diferentes dimensiones. Es decir si se trata de países que a la vez que reciben trabajadores extranjeros, sufren la emigración de sus nacionales. Por tales razones una política pública migratoria debe de ir acompañada de una política exterior de empleo. La diferencia entre ambas políticas consiste en que la primera se refiere a la acción que el Estado emprende para administrar los flujos de personas que ingresan a su territorio nacional y la segunda, de acuerdo con Abella (1997) se refiere al tratamiento administrativo estatal que se le ha de dar a la emigración de trabajadores. Se trata entonces de emprender una política integral que le de un tratamiento adecuado a los flujos migratorios en una doble vía desde el Estado.

Ambos tipos de de políticas deben de ser coherentes entre sí. Deberían referirse al tratamiento administrativo que ha de dársele a la migración como un desafío humano, más que un fenómeno puramente de mercado. No obstante, es importante rescatar las diferencias entre los dos tipos de tratamientos. Para el Estado receptor implica tener condiciones adecuadas para recibir a los contingentes de migrantes. El país que recibe tiene unos elementos dados que debe de considerar a la hora de plantear una política pública migratoria como por ejemplo:

\section{Elementos estructurales}

Vínculos previos entre los países implicados en la migración (factores históricos)

Factores culturales y étnicos

Factores económicos

Factores políticos

Factores sociales

\section{Elementos Coyunturales}

Cambios internacionales (globalización, integración, tratados comerciales)

Crisis (políticas, militares, naturales)

Sociedad civil y opinión pública

Redes sociales de migrantes

\footnotetext{
${ }^{5}$ Para el esquema que se plantea en este artículo, se cambió la palabra control por la de administración por considerarse más adecuada al análisis que se desarrolla.
} 


\section{Normativa existente}

Normativa nacional

Normativa internacional

\section{Elementos transversales}

Equidad de género

Derechos humanos

Considerando en las acciones del Estado este tipo de elementos, la política tendría una dirección más acorde con las necesidades de las personas involucradas en el proceso migratorio. Principalmente, porque los que resultan ser más afectados son los migrantes trabajadores. Cuando se mencionaba anteriormente que existen diferentes tipos de migrantes, se aclaró que la migración no es la misma para los diferentes estratos de la sociedad. El migrante trabajador, el que llega a buscar un empleo en un país diferente al que nació, ya viene perdiendo. La mayoría de las veces porque no han tenido la oportunidad de un empleo en su país. Por lo tanto, son desempleados que no cuentan con ahorros que les garanticen las condiciones mínimas para vivir. Al llegar al país de destino, esta situación se agrava, debido a que no solo no tienen ahorros, sino que se arriesgan a contar solo con el capital social ${ }^{6}$ que las redes de migrantes pueden facilitarles desde la solidaridad, principalmente. Si bien estas redes son significativamente importantes para la consecución de un empleo en el país receptor, no les garantiza a los migrantes sus derechos ${ }^{7}$ y posibilidades de progresar.

Cuando una política pública dirigida a las migraciones solo se centra en la acción policial, deja de lado aspectos positivos que podrían beneficiar a las poblaciones de los países involucrados en el proceso migratorio. Una política pública migratoria acertada es aquella que toma en consideración que el fenómeno a tratar debe de abordarse desde una visión que determine la relación costo beneficio de la migración desde diferentes aristas. Es decir que no se enfoque solo a la vigilancia y salvaguarda de las fronteras. "Una migración internacional ordenada puede producir efectos positivos tanto en las comunidades de origen como de destino. La migración ofrece también la posibilidad de facilitar la transferencia de conocimientos prácticos y de contribuir al enriquecimiento cultural” (Naciones Unidas, 2002: 1). Quizás estos sean aspectos difíciles de cuantificar en el corto plazo. Solo se pueden valorar con el paso del tiempo. Cuando permitimos que las expresiones artísticas y la cultura se enriquezca en su ambiente natural: la diversidad. En el campo económico, si se pueden cuantificar en el corto plazo los beneficios de la migración. Por citar un ejemplo, las remesas hacia Costa Rica en 2002, representaron el $1.3 \%$ del PIB. Un 17\% de los nicaragüenses envían un promedio de \$100 mensuales hacia Nicaragua y un 20\% de los costarricenses que trabajan en Estados Unidos envía un

\footnotetext{
${ }^{6}$ De acuerdo con Bourdieu (2001: 102-103) el capital social es el agregado de recursos y potenciales que están ligados a la posesión de una red duradera de relaciones más o menos institucionalizada de conocimiento y de reconocimiento mutuo - o en otras palabras a la membresía de un grupo - que provee a cada uno de sus miembros el respaldo de capital poseído colectivamente, una credencial que los "intitula” al crédito en los diferentes sentidos de la palabra.

${ }^{7}$ Para ampliar información sobre este caso en particular ver Borge (2004) "Migraciones de Nicaragüenses hacia Costa Rica, análisis de dos redes sociales”.
} 
promedio de \$500 mensuales hacia Costa Rica. (Barquero, 2005). Lo anterior, deja al descubierto el aporte significativo que los trabajadores migrantes hacen a la economía de sus países. Eso sin tomar en consideración los envíos de dinero que se realizan sin utilizar los canales bancarios.

Desde una política exterior de empleo, el país emisor puede adoptar un tipo de régimen político de acuerdo con los factores anteriormente mencionados, según lo que propone Abella (1997:8-10):

El Laissez-faire. Se refiere a que el Estado deja que la emigración sea regulada por las fuerzas del mercado. Este tipo de régimen es aplicado actualmente por países de altos ingresos como por ejemplo Reino Unido y Portugal. Es decir que la política exterior de empleo utiliza los mismos instrumentos que la política doméstica para su regulación. El rol del mercado es muy fuerte. La migración es espontánea desde movimientos no organizados. La transferencia de las ganancias se hace a través de los canales de la banca; la protección de los migrantes es únicamente referida a las leyes estatales de empleo y el retorno y la reintegración son totalmente espontáneos.

El Sistema regulado. El Estado de origen adopta leyes y regulaciones para proteger a sus nacionales en el mercado de trabajo internacional. El Estado se convierte en un intermediario entre los demandantes y los oferentes de empleo. La política se dirige principalmente a la protección de los trabajadores. Los requerimientos institucionales se refieren a leyes de reclutamiento o contratación, con estándares mínimos basados en un cuerpo regulatorio. El mercado ejerce un papel regulador; la migración se organiza de manera espontánea pero solo a través de canales autorizados; la seguridad para el empleo en el extranjero la respaldan agencias privadas; la colocación o el reclutamiento es libre o lo realizan agencias privadas, la transferencia de ganancias se canaliza por la banca; la protección de los migrantes está amparada a las leyes estatales de empleo y de contratación. Al igual que en el Laissez Faire, el retorno y la reintegración son totalmente espontáneos. Este es el caso de la India.

Sistema del Estado administrador. En este sistema el Estado planea y promociona una política de empleo activa, basado en los estándares institucionales mínimos; el mercado es regulado por el Estado, la migración es guiada por Estado quien además promociona el empleo en el exterior para sus nacionales. Por otra parte, el reclutamiento lo dirigen tanto las empresas privadas como agencias gubernamentales. La transferencia de ganancias se hace a través de canales regulares incentivados por el Estado; la protección de los migrantes se hace por medio de acuerdos binacionales; y el retorno y la reintegración son incentivados por el Estado. Como ejemplos, para este caso existen Filipinas y Pakistán.

Estado monopólico. El Estado asume un rol exclusivo en la responsabilidad de organizar la migración laboral de sus ciudadanos. El contenido de la política es dirigido al empleo; El Estado negocia como un monopolio las necesidades por mano de obra, suple las necesidades en cuanto a la seguridad de los trabajos; las transferencias de las ganancias se realizan por medio de una agencia bancaria estatal; la protección de los migrantes la asume el estado emisor como una responsabilidad directa; y en lo que se refiere al retorno 
y la reintegración el Estado asume la responsabilidad por el empleo. Ejemplos de aplicación de este tipo de régimen son China y Vietnam.

Para que ambos tipos de políticas: la exterior de empleo de parte del país emisor y las públicas, correspondiente al país receptor, logren el propósito de administrar las migraciones laborales en beneficio de las personas y de las sociedades implicadas en este proceso, existen por ejemplo acuerdos bilaterales (ver dibujo N.1). Con este tipo de instrumentos es posible darle coherencia a las acciones emprendidas por las administraciones implicadas ${ }^{8}$. Los acuerdos bilaterales son una posibilidad que han demostrado tener un efecto positivo en diferentes contextos internacionales, como es el caso de España con respecto a países de los que reciben una mayor inmigración ${ }^{9}$. Este país ha suscrito convenios bilaterales con Polonia, Rumania, Bulgaria, Ecuador, Colombia, República Dominicana y Marruecos $^{10}$. Estos acuerdos contemplan la administración de la oferta y la demanda laboral de mano de obra migrante, los derechos y condiciones laborales y sociales de este colectivo, la regulación de los trabajadores temporales y la regularización del retorno. Aunado a una política pública migratoria que contempla acuerdos bilaterales, España cuenta con veintidós Oficinas de Extranjeros, que buscan una mejor gestión en materia migratoria. De la misma manera, con el fin de agilizar los trámites en permisos de trabajo y residencia de los extranjeros en España existen convenios de colaboración interinstitucionales entre las diferentes instancias involucradas a nivel nacional con la temática migratoria (Ministerio del Interior, 2002).

\footnotetext{
${ }^{8}$ Es importante tomar en consideración que la migración no va en solo sentido, es decir que la mayoría de los países son emisores y receptores de migrantes en mayor o menor grado. Por ejemplo en los Estados Unidos, por cada cuatro personas que llegan una se va; en Alemania y Australia, por cada tres personas que llegan, dos se van; en el Japón y en Suiza por cada tres personas que llegan, una se va (OIM, 2005).

${ }^{9}$ España ha realizado convenios bilaterales con los países que más han impactado a esta sociedad en materia de migración. Un ejemplo es el convenio realizado con Ecuador que contempla regularizar los flujos migratorios, garantizar la igualdad de derechos en relación con los trabajadores nacionales y estimular mediante incentivos económicos, capacitación, asesoramiento y asistencia técnica el empleo en el país de origen de los migrantes. Para operacionalizar el acuerdo se estableció una oficina en Quito en la que se nombra una comisión encargada de la selección de los trabajadores migrantes ecuatorianos de una forma técnica, ordenada y sistematizada. Los trabajadores seleccionados, reciben una visa de trabajo y un contrato de trabajo con lo que pueden viajar a España en condiciones de legalidad con el apoyo del gobierno de Ecuador. La Organización Mundial para las Migraciones (OIM) ofrece asesoría técnica y administrativa en este proceso. (Morales, 2005:1). El procedimiento inicia en la Embajada de España en Quito que comunican a las autoridades ecuatorianas el número y las características de las necesidades de mano de obra de acuerdo con las ofertas de empleo. Por su parte las autoridades ecuatorianas dan a conocer a las autoridades españolas, la demanda por trabajo existente en Ecuador de quienes deseen trasladarse a España. (Acuerdo entre la República de Ecuador y el Reino de España relativo a la regulación y ordenación de los flujos migratorios, 2001).

10 También tiene convenios bilaterales de readmisión con Francia, Portugal, Italia, Suiza, Polonia, Eslovaquia, Estonia, Letonia, Lituania, Rumania, Bulgaria, Marruecos, Argelia, Nigeria y Guinea-Bissau. (Ministerio del Interior, 2002).
} 
Dibujo N. 1

Políticas migratorias laborales

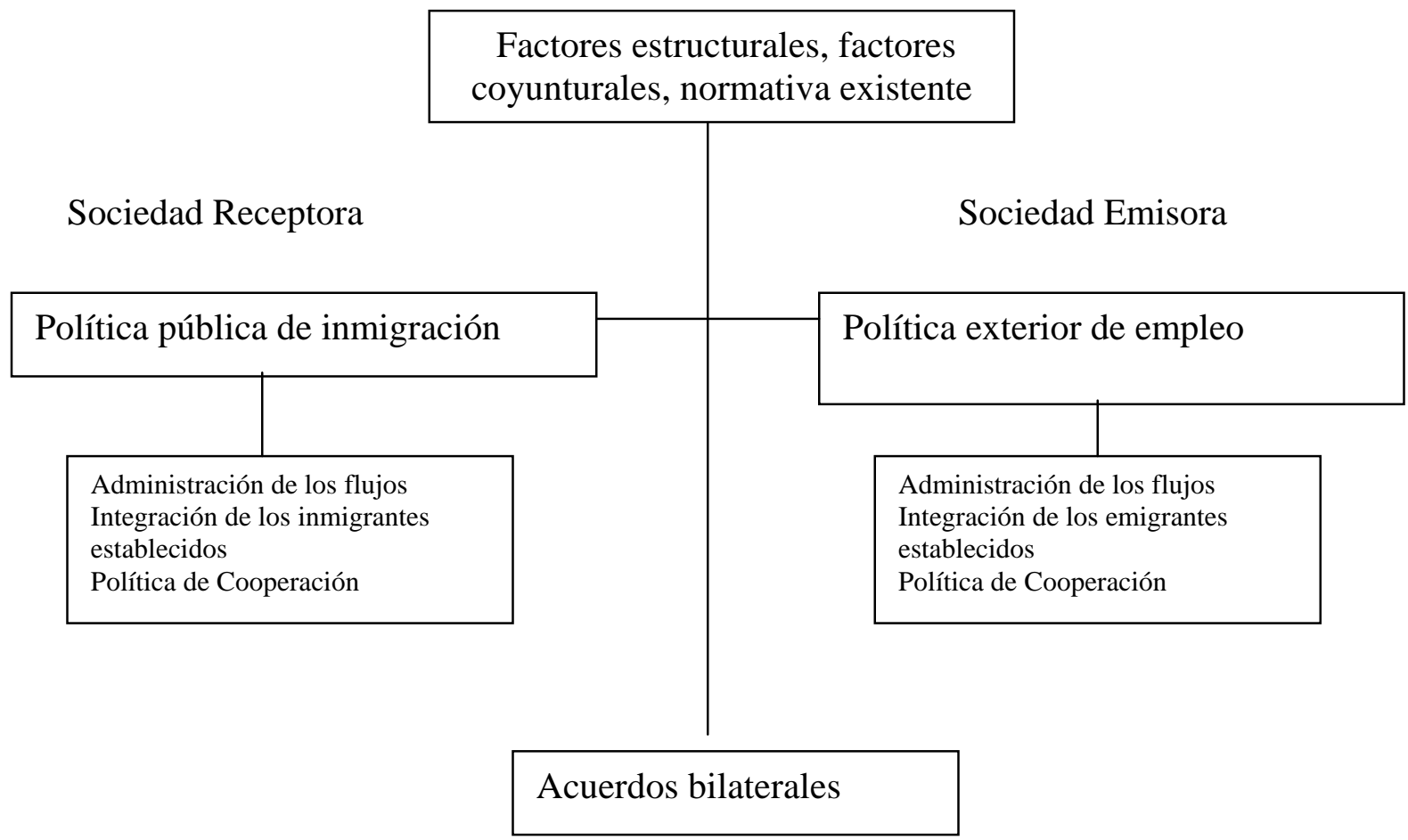

Los modelos aplicados en otros contextos pueden ayudar a clarificar los caminos más adecuados para ser tomados en consideración por países que experimentan el fenómeno de la migración internacional. Si bien el contingente de migrantes internacionales sigue concentrándose en relativamente pocos países ${ }^{11}$ Costa Rica experimenta una presión migratoria que corresponde a un $6 \%$ de su población ${ }^{12}$ que en términos comparativos es un contingente importante en relación con datos de las regiones que experimentan las mayores presiones migratorias a nivel mundial ${ }^{13}$.

11 De acuerdos con Organización Internacional para las Migraciones (OIM) el 75\% de todos los migrantes internacionales se encuentra en un $12 \%$ de todos los países. Los tres principales países receptores de migrantes son los Estados Unidos, con 35 millones de migrantes, que registra el 20\% del contingente mundial de migrantes, La Federación de Rusia, con 13,3 millones de migrantes, que registra el 7,6\% del contingente mundial de migrantes; y Alemania con 7,3 millones de migrantes, que registra el 4,2\% del contingente mundial de migrantes. En el caso de Rusia el dato está sesgado por la situación política de reconfiguración fronteriza y con respecto a Alemania, es necesario revisar si los datos se refieren al impacto de la integración de Alemania Democrática o de los contingentes provenientes de Turquía.

12 Datos del censo realizado en Costa Rica en el 2000

${ }^{13}$ De acuerdo con la OIM, Europa tiene el 7,7\% de migrantes en relación con su población total; Asia el 1,4\%; América del Norte el 13\%; África el 2\%; América Latina el 1,1\% y Australia el 18,7\%. 


\section{CONCLUSIONES}

No existe una política pública migratoria ni una política exterior de empleo en Costa Rica que administre y gestione el este fenómeno, no solo para los extranjeros que ingresan en busca de trabajo, sino que tampoco para los nacionales que se van a trabajar a otros países. La existencia de unas cuantas acciones de emergencia para paliar la situación no permite tener un acercamiento con la realidad a la que se enfrentan Costa Rica y Nicaragua con respecto a la migración. Es decir que no se cuenta con un programa integral que le de un tratamiento de corto, mediano y largo plazo a las migraciones. Esto podría deberse a la "omnipotencia y/o responsabilidad del Estado; a las visiones distorsionadas y/o prejuiciosas del fenómeno migratorio y de las reales capacidades de respuesta institucional al mismo; a la predominancia de los ideologismos sobre el análisis objetivo; a la imposición de los intereses de algunos sectores sobre el conjunto de la población; a la falta de consideración sobre los derechos humanos en el momento de diseñar o ejecutar las políticas; en definitiva, al intento de tratar de imponer lógicas burocrático- administrativas ideales a una realidad cuya lógica de existencia y reproducción proviene de la compleja trama de los procesos socioeconómicos" (Mármora, 2002: 81). Por otra parte, en tanto se siga apuntando a un colectivo como responsable del deterioro de los diferentes servicios que presta el Estado, no se resolverá el tema migratorio laboral, ni otros de de similar importancia. Sería importante investigar a qué se debe el aumento en la pobreza, la inseguridad ciudadana, el aumento de la deserción escolar a niveles sin precedentes, el deterioro en los servicios de salud, la vivienda, el descuido de la infraestructura vial, el mal uso de los recursos del Estado, entre otros factores, para promover políticas más cercanas a la realidad nacional y no justificar un problema con otro. Este tipo de actitudes solo hacen que las propuestas de parte del Estado se distorsionen y se desperdicien recursos en un intento de resolver problemas inexistentes o mal planteados.

Desde las investigaciones que se realizan en torno al fenómeno migratorio internacional en Costa Rica, se hace evidente que el hecho de no administrar las migraciones es solo uno de los impactos de no administrar los grandes temas a nivel nacional. Es decir que, el Estado costarricense tiene grandes deficiencias para canalizar las demandas de sus ciudadanos en áreas prioritarias como la seguridad social, la educación, la vivienda, el empleo y por lo tanto tampoco lo hace con respecto a la inmigración de trabajadores.

No existen evidencias de impactos significativos de parte de los trabajadores migrantes en los servicios de salud, la mortalidad, las tendencias de la pobreza y el empleo. Por otra parte, el ingreso de nicaragüenses tiende a disminuir, mientras que la salida de nacionales hacia Estados Unidos aumenta. (Barquero, 2005), lo que en definitiva hay que tomar en consideración para plantear una política pública y una política exterior de empleo acorde con la realidad migratoria. De lo contrario, el Estado invertirá recursos en administrar un fenómeno inexistente, por ser abordado desde aristas distorsionadas.

La ley de migración de 2005, solo contempla una de las dimensiones de la migración cual es la seguridad nacional, limitándose a la restricción más que a la administración de los trabajadores migrantes que se insertan en actividades económicas de vital importancia 
para la economía costarricense. Es una ley que no incluye la participación de los diferentes grupos de presión ni a los investigadores del tema. Que no se fundamenta en la opinión pública, y que no ha dimensionado el impacto y las consecuencias en la economía y las relaciones comerciales y diplomáticas con Nicaragua y en consecuencia con el resto de los países de la región. El problema no consiste en si en la existencia o no de una ley, el problema es no conocer las dimensiones del fenómeno migratorio y dictar una ley que podría o no resultar positiva, basada en un sistema prueba error, que pone en riesgo a las sociedades involucradas en esta dinámica. Si la política es restrictiva porque el Estado considera que es necesario proteger la mano de obra nativa, también debería de considerar las consecuencias para el mercado laboral de esa política. Porque la otra cara de la moneda de una política absolutamente restrictiva en función de criterios de seguridad es que puede afectar negativamente el aprovisionamiento necesario de mano de obra en mercados de trabajo con demanda insatisfecha. A la inversa, políticas de promoción emigratoria indiscriminada pueden producir escasez de oferta en sectores laborales (Mármora, 1997). De allí la importancia de conocer el costo beneficio de las decisiones en materia de políticas públicas, sin olvidar que las leyes pueden proteger o marginar a los individuos dependiendo del espíritu bajo el cual fueron creadas.

Es necesario emprender acciones diferenciando las situaciones ideales de las reales y de las posibles $^{14}$ (Mármora, 2002:79), sin perder de vista que la migración internacional es un desafío humano y no un fenómeno de mercado ${ }^{15}$; que desde esa dimensión su tratamiento debe ser dirigido a las personas más que a las estructuras, desde una visión multidisciplinaria e interinstitucional; que incluya la participación de las administraciones públicas implicadas en el tema. Quizás, una manera de administrar las políticas públicas complejas, sea llevando a cabo pequeñas acciones en aspectos prioritarios. El primero de ellos podría ser desmitificar al migrante, dimensionarlo como ser humano que aporta trabajo, pero que además es sujeto de derechos. Los decisores públicos, tendrían que acordarse que administrar las acciones del Estado tiene el propósito de hacer de la sociedad un mejor lugar para vivir, un espacio para procurar el desarrollo de sus habitantes, donde se les permita a las personas hacer aportes de toda índole, independientemente de su nacionalidad.

\footnotetext{
${ }^{14}$ Según Mármora (2002: 79-80) la situación ideal es la planteada como deseable, en función de la relación óptima entre las migraciones y la situación social, económica, cultural y política de la sociedad. La situación real es la situación migratoria tal como se da. Y la posible es la síntesis que deriva de la ideal y la real, con los límites impuestos por los elementos de gobernabilidad disponibles y los derechos del individuo, las colectividades y el Estado.

${ }^{15}$ Aunque los procesos de globalización influyan en los patrones migratorios, no se puede considerar a las personas objetos de mercado.
} 


\section{BIBLIOGRAFÍA}

Abella, M (1997). Sending workers abroad. A manual for low and middle income countries. Geneva: Internacional Labour Office (ILO)

Acuerdo entre la República del Ecuador y el Reino de España relativo a la regulación y ordenación de los flujos migratorios.

En http//www.mmrree.gov.ec/mre/documentos/tratados/espana1.pdf21/09/2005

Aguilar, L (1992) la hechura de las políticas. México, Miguel Ángel Porrúa editor.

Asamblea Legislativa de la República de Costa Rica. Ley de migración y Extranjería.

Barquero, J. (2005) La migración internacional en Costa Rica: estado actual y consecuencias. Charla elaborada para el curso de Actualización y mejoramiento en el Área de Educación Cívica, organizada por la Escuela de Historia de la Universidad de Costa Rica, la Asociación Ciudadanía Activa y el Colegio de Licenciados y Profesores. San José.

Bourdieu (2001) The forms of capital. In Granovetter, M. and R. Swedberg The sociology of economic life. (Second edition). Colorado: Westview Press.

Borge (2004) Migraciones de nicaragüenses hacia Costa Rica, análisis de dos redes sociales. Tesis sometida a la consideración del Programa de Estudios de Posgrado en Gobierno y Políticas Públicas para optar al grado de Doctor. Universidad de Costa Rica

Criado, M.J. (2001) La línea quebrada: historias de vida de migrantes. Madrid: Consejo Económico y Social.

Informe sobre la Redacción final del texto aprobado en primer debate (27 de octubre de 2005) Plenario, Cuarta legislatura, segundo período de sesiones ordinarias. Departamento de comisiones legislativas, Comisión Permanente Especial de Redacción.

Jackson, J.A. (1986) Migration, Londres, Longman.

Ministerio del Interior, Oficina de Relaciones Informativas y Sociales (2002) Balance 2002 Delegación del Gobierno para la Extranjería y la Inmigración. Madrid

Mármora, L. (2002) Las políticas de migraciones internacionales. Buenos Aires: Paidós.

Mármora, L. (1997) Políticas y administración para la gobernabilidad migratoria. En documento mimeografiado, Panamá

Meny, I. and Thoenig J. (1992) Las políticas públicas. Barcelona: Ariel Ciencia Política. 
Morales, A. (2005) Los cambios en los flujos migratorios y sus impactos políticos, económcos y jurídicos.

En http//www.sela.org/public_html/AA2K2/esp/docs/coop/migra/spsmirdi1802/spsmirdi18... 22/09/2005

OIM

http://www.iom.int/en/PDF_Files/wmr2005_presskit/wmr_facts_and_figures/WMR_Fact s_and_Figures_SP.pdf

Oficina Internacional del Trabajo (1999) Trabajadores Migrantes. Informe III, Ginebra: OIT

Ley de extranjería (2000) Texto íntegro de la ley de extranjería (En vigor desde 23-012001). Ley orgánica 8/2000, de 22 de diciembre, de reforma de Ley Orgánica 4/2000, de 11 de enero, sobre derechos y libertades de los extranjeros en España y su integración social. (Publicada en el BOE 23.12.2000).

En http://canales.laverdad.es/especiales/leyextran/

Vargas, J.C. (2004) Migración internacional en Costa Rica: características y tendencias en el epríodo 1990-2003, en Décimo informe sobre el estado de la nación en desarrollo humano sostenible. San José, Proyecto Estado de la Nación. 